\title{
CC:DA Report from ALA Mid-Winter
}

by Donna J. Wells

The CC:DA (Committee on Cataloging: Description and Access) met over two days in Seattle this winter. The Committee currently has two task forces: 3-R (RDA Toolkit Restructure and Redesign) and the Virtual Participation Task Force. The Virtual Participation group is studying the viability of online attendance at the biannual meetings. They are at a very preliminary stage and would like to try, at the annual meeting in June, to have just two virtual participants. They are recommending that the online attendees be limited to those for whom physical attendance is impossible.

A motion was made to create a new task force to update the policy and procedures manual which has not been updated since 2011. Much time of the meeting was filled with reports from the Library of Congress, NARDAC (North American RDA Committee), the committee webmaster, PCC liaison, the 3-R task force, and the representative from ALA publishing. The full text of these reports are available on the Committee blog (https://alcts.ala.org/ccdablog/?cat=33).

Here are the highlights of these reports:

- New content was added to the Z pages in the NACO documents.

- Multiple subdivisions such as Buddhism, Christianity, etc. have been dropped because the terms were causing issues with linked data. Each term will now have an established heading.

- $\quad$ PCC has changed its method for gathering data and apologized profusely for the recurring password changes-it is a government security requirement.

- $\quad$ RDA Toolkit - The beta version is being updated almost daily. All Toolkit users are begged to test the beta site and look for flaws, suggest improvements, and give feedback. The project is slated to be completed by the end of 2019, at the latest but the goal is April or June. There is a YouTube channel for RDA. Latin American libraries are joining and participating in enhancing RDA. The translation of the Toolkit is currently in process. The new version will have a graphic browser. The new RDA is much larger than the past version running to 3000 pages of print, so work is being done to find a viable solution for a print version.

Day Two was given over to "A Deeper Dive into RDA" which was three hours of very technical issues, nomenclature, and discussion.

The actual work of the Committee will resume (hopefully) at the annual meeting in June but only after the release of the new Toolkit.

Donna J. Wells is the Associate Director and Head of Technical Services at Southeastern Baptist Theological Seminary. 